\title{
CHARACTERIZING SPATIAL AND TEMPORAL TRENDS OF SOIL AND SURFACE PROPERTIES CHANGES IN AN AREA WITH URBAN, BARE SOIL AND WETLAND COVERS: A 30-YEAR CASE STUDY IN GOMISHAN, IRAN
}

\author{
S. K. Alavipanah ${ }^{1, *}$, M. Konyushkova ${ }^{2}$, S. Hamzeh ${ }^{1}$, A. A. Kakroodi ${ }^{1}$, A. Heidari ${ }^{3}$, M. K. Firozjaei ${ }^{1}$, N. Mijani ${ }^{1}$ \\ ${ }^{1}$ Dept. of Remote Sensing and GIS, Faculty of Geography, University of Tehran, Tehran, Iran - (salavipa, saeid.hamzeh, \\ a.a.kakroodi, mohammad.karimi.f, naeim.mijani)@ut.ac.ir \\ ${ }^{2}$ Lomonosov Moscow State University, Moscow - mkon@inbox.ru \\ ${ }^{3}$ Dept. of Soil Science, Faculty of Agriculture, University of Tehran, Tehran, Iran - ahaidari@ut.ac.ir
}

KEY WORDS: Spatial and Temporal Changes, Surface Characteristics, Soil, Landsat, MODIS, Gomishan.

\begin{abstract}
:
Climate is one most important factors that can reconstructs the formation of soils. Accordingly, the objective of this study is characterizing spatial and temporal trends of soil and surface properties changes in Gomishan region during the period of 2017-1987. For this purpose, 432 monthly product of LST (MOD11C3) and vegetation cover (MOD13C2) of MODIS sensor and 3 Landsat images were used. Single-channel algorithm and various spectral indexes were used to modeling of Land surface temperature (LST) and surface properties including brightness, greenness, wetness and salinity. Then, based on the soil line analyse, pixels with the full cover of soil were extracted. Finally, trend of LST and surface properties variations were investigated for these pixels and whole studied area. The average of LST and vegetation cover changes in January, February, March and April are higher than other months. The variance of LST and surface properties for Gomishan wetland was higher than other regions of the studied area. The values of Soil salinity index in 2000 year was higher than 1987 and 2017 years. The LST of pixels with full cover of soil in the north of study area was higher than the south. Also, wetness of these pixels in the northern regions is lower than the southern regions of the study area. The results of study indicate, spatial and temporal variations of the surface properties of the Gomishan area derived from remotesensing data were high.
\end{abstract}

\section{INTRODUCTION}

Soil is a very important component of ecosystem stability. The soil's ability to perform a specific process or use is the concept of soil quality in the ecosystem. In previous study, chemical, physical and biological factors have been proposed to determine the effects of ecosystem destruction and soil quality (Seybold et al. 1999).

Soil is formed as a bed of life and a place of plant growth as a result of the interaction of soil tillage factors including climate, living organisms, maternal materials, and posture and height over time. Among these factors, the climate has a very important impact on the formation and development of soil (Brady and Weil 2013; Panagopoulos and Hatzistathis 1995). Climate is the most important factor that alone determines the composition of plant species in a region, the amount of plant products, and the intensity of microbial activity in the soil. Climatological factors are active on a large scale and affect soil characteristics. Soil organic carbon is one of the most important factors affecting soil quality and has great potential for change due to climate change and human management.

Climate conditions through climatic indicators such as rainfall, evapotranspiration, wind, and radiation can affect some soil tillage processes (Jafari and Sarmadian 2003). Buol et al. (2011) suggested at the beginning of soil formation, bedrock factor is important and often affects the soil properties, but when the soil horizons are formed and the thickness of the soil increases over time, the climate effect of soiling on physical, chemical and biological properties of soil is more than other factors (Buol et al. 2011).

\footnotetext{
* Corresponding author
}

Therefore, recognizing the effects of climate on soil quality, especially in arid and semi-arid regions, is essential for the correct management of these soils (Lal 2004; Wagenet and Hutson 1997). Changing climate creates an additional pressure that could change or threaten ecosystems.

Soil properties and processes, including organic matter decomposition, leaching and soil moisture regimes, will be affected by rising temperatures (Davidson and Janssens 2006). Soil Erosion and degradation are likely to exacerbate the adverse effects of increasing air temperature on crops (Kirschbaum 1995). Climate change may lead to increased erosion in some areas, due to intense rainfall and increase wind speed (Peizhen et al. 2001).

Climate change can also exacerbate desertification by changing temperature, rainfall and wind. The water holding capacity depends on the degree of soil degradation. Due to poor land management, soils can lose fertility as a result of climate change and thus exposed to degradation. The Land Surface Temperature (LST) and surface biophysical characteristics are the parameters that affect the climatic conditions of a region. Accordingly, the objective of this study is characterizing spatial and temporal trends of soil and surface properties changes in Gomishan region during the period of 2017-1987.

\section{PROPOSED METHOD}

\subsection{Study area}

The Gomishan region, located in the North of Iran $\left(53^{\circ} 42^{\prime}\right.$ to $54^{\circ} 21^{\prime} \mathrm{E}$ longitude and from $37^{\circ} 50^{\prime}$ to $38^{\circ} 15^{\prime} \mathrm{N}$ latitude), covers an area of $3522 \mathrm{~km}^{2}$. The minimum, maximum and average 
elevation of the study area are $-55,54$ and -23 meters from the mean sea level, respectively. The region's climate is semi-arid, and the average long-term temperature and annual rainfall of the region are $17.6^{\circ} \mathrm{C}$ and $381 \mathrm{~mm}$, respectively. The geographic location of the studied area is shown in Figure 1.
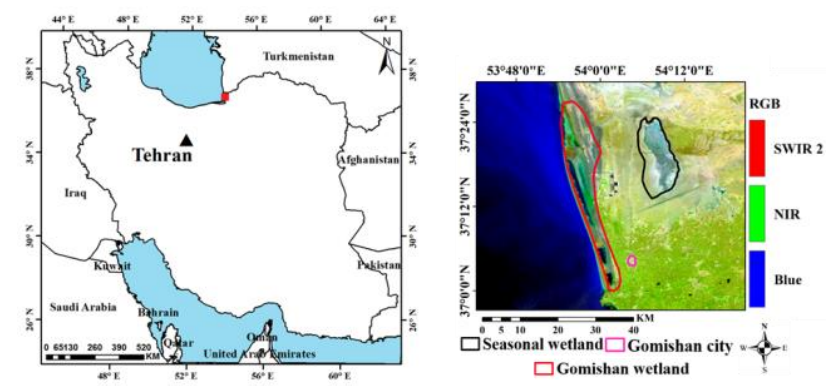

Figure 1. Location of case study

\subsection{Data}

In this study, Landsat and MODIS imagry were used to investigate the changes in LST and surface biophysical characteristics of the Gomishan area, during the last decades. In this study, 435 products and images of MODIS and Landsat were used. Landsat images related to Landsat 5 (July 16, 1987 and July 19, 2000) and Landsat 8 (July 18, 2017) were used to modeling of LST and various surface biophysical parameters. Also, monthly LST products (MOD11C3) and vegetation cover (MOD13C2) of the MODIS sensor were used for a period of 18 years from the beginning of 2000 to the end of 2017.

\subsection{Method}

In the present study, the first step, the trend of LST and vegetation variation in the studied area for the 2000 to 2017 period were monitored by monthly products of the LST and vegetation cover of the MODIS. To study the temporal changes, the average of LST and vegetation cover of the whole study area, city and wetland of Gomishan and seasonal wetland were investigated. In order to spatial changes investigation, the variance of LST and vegetation cover values for each pixel was calculated for the period 2000 to 2017, and a map of LST and vegetation cover variance was produced. Monthly products of LST and vegetation cover of the MODIS have appropriate temporal resolution, but the spatial resolution of these products is inappropriate.

Accordingly, in the second step, the spatial and temporal changes of LST and biophysical properties of the studied area was investigated for the period 1987 to 2017 by Landsat imagery. In this study, the single channel algorithm was used to LST calculation (Jimenez-Munoz et al. 2014; Sobrino et al. 2004). Also, Normalized Difference Built-up Index (NDBI) (Zha et al. 2003), Normalized Difference Vegetation Index (NDVI) (Tucker 1979) and Normalized Difference Water Index (NDWI) (Gao 1996), albedo (Liang 2001), wetness (Baig et al. 2014), brightness (Baig et al. 2014), Normalized Difference Salinity Index (NDSI) and Salinity Index 1 (SI 1) were used to modeling of various surface biophysical characteristics.

The average of LST and surface biophysical characteristics including Brightness, Greenness, Wetness and salinity were investigated in whole study area, Gomishan city and wetland, and
Seasonal wetland scale. Also, the variance parameter was used to study the spatial and temporal changes of LST and surface characteristics including LST, greenness, brightness, wetness, and salinity.

In the third step, pixels with the full cover of soil at all dates were extracted based on the soil line in the red and near infrared bands feature space. Finally, trend of LST and biophysical characteristics variations for these pixels during 1987 to 2017 period were studied.

\section{RESULTS}

The results of the surveys show that, the average of LST and vegetation cover of the study area varies for different months and years. The changes of LST and vegetation cover average in January, February, March and April are higher than others.

Also, the variance of the LST and vegetation cover average for different regions of studied area are different, and the distribution of high variance values are spatially varies in different months. In January, February, March, April and May the values of LST and vegetation cover variance for the marginal areas of the Caspian Sea and the southeastern region of the study area, which is the area of agriculture, is high. But for June, July, August, September, October, November and December, high values of LST and vegetation cover variance are limited to the regions of near Caspian Sea.

High values of variance in a pixel indicate significant changes in LST or vegetation cover over the time period studied in that pixel and vice versa (Figure 2).
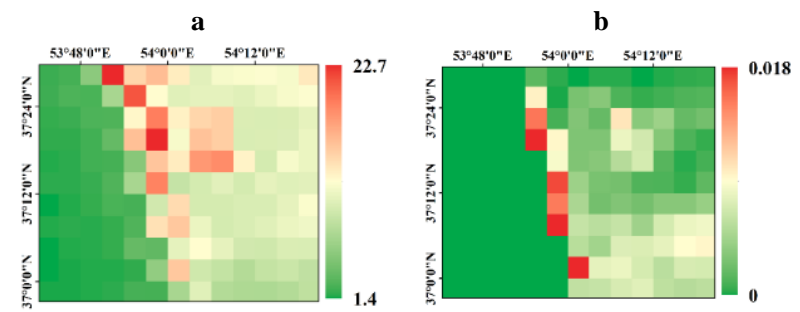

Figure 2. Variance maps of (a) LST and (b) vegetation cover during of 2000-2017.

The maximum LST changes for the study area are related to seasonal wetlands and Gomishan wetland. Wetland, probably due to the water level of the wetlands. Generally, for the study area, changes of LST and vegetation cover can be attributed to changes of the surface biophysical characteristics, increased human activity, increased salt-marsh lands, and the advance and subsequent water level of the Caspian Sea and changes of the water level of the Gomishan wetland.

To investigate the surface changes of the studied area with suitable spatial resolution, different surface characteristics such as LST, vegetation cover, wetness, Brightness, and salinity were modeled based on Landsat images. The results indicate spatial and temporal variation of surface characteristics of the studied area in 1987-2017 period is high. Spatially, the maximum changes of surface properties (LST, vegetation cover, Brightness, Wetness and salinity) in the studied area are related to Gomishan wetland (Figure 3). 

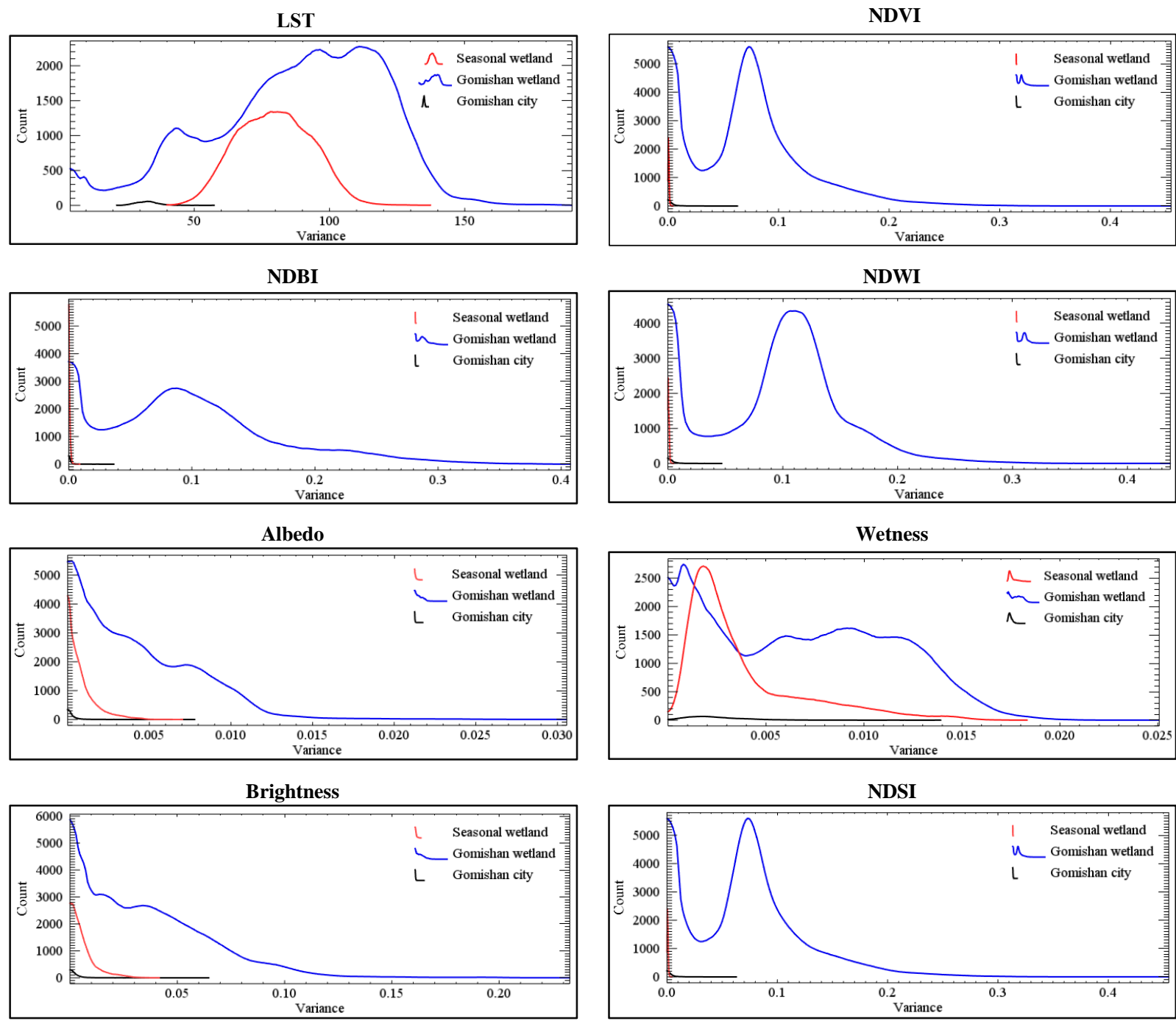

SI 1

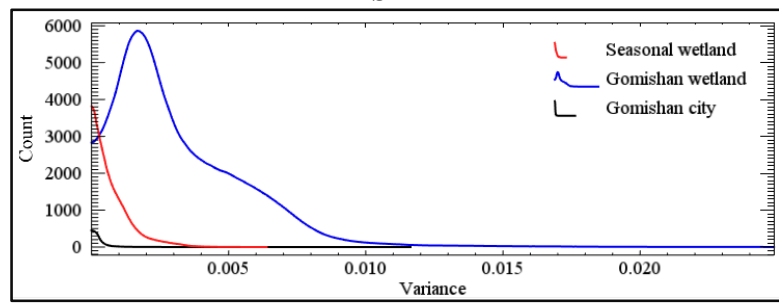

Figure 3. Histogram of variance values of biophysical properties of Gemishan city and wetland, and seasonal wetland

The average of surface biophysical characteristics variance of the area was calculated and shown in Figure 4.

Gomishan city and wetland, seasonal wetland, and study

LST

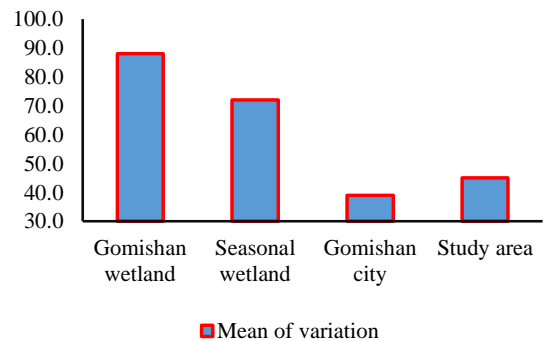

NDVI

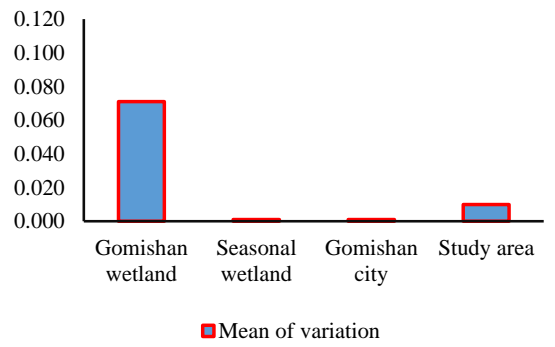


NDBI

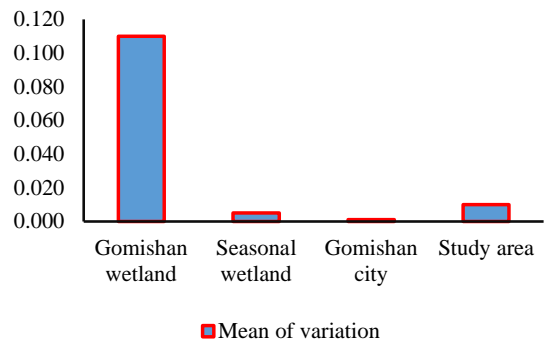

Albedo

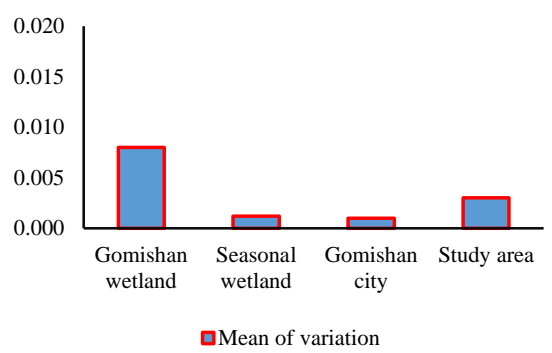

Brightness

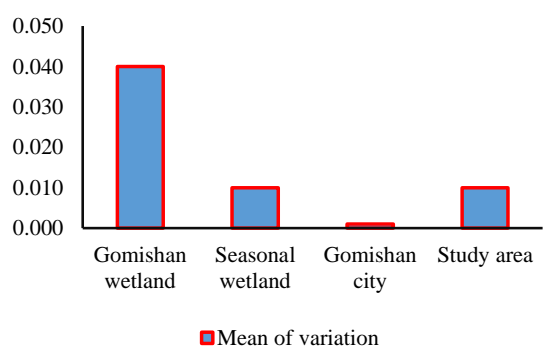

NDWI

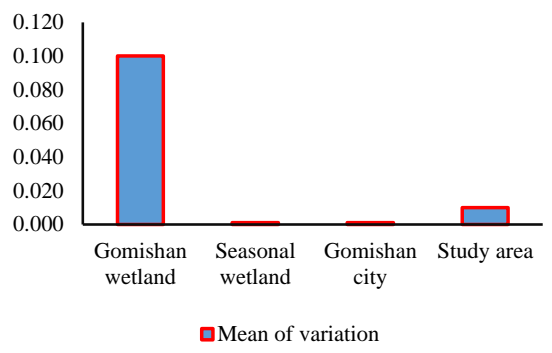

Wetness

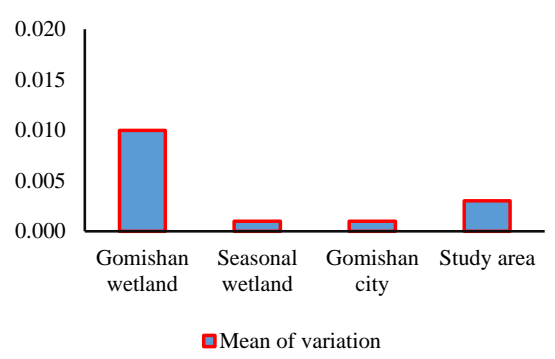

NDSI

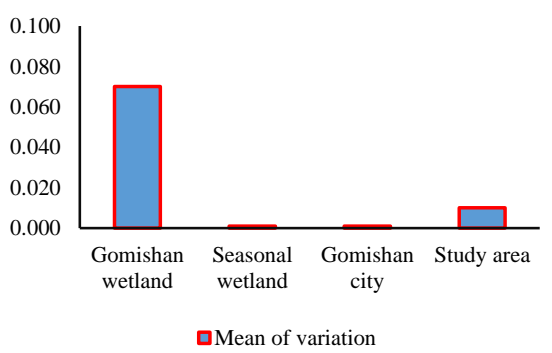

SI 1

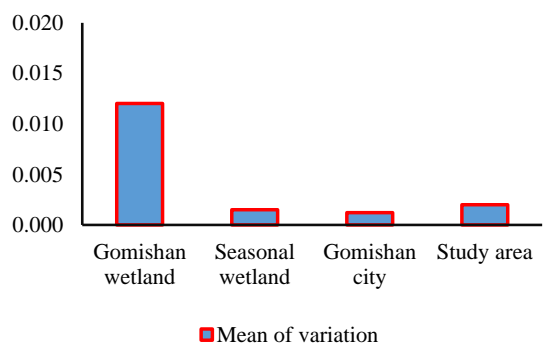

Figure 4. The mean of variation of the surface biophysical characteristics of the Gomishan city and wetland, seasonal wetland, and study area from 1987-2017.

Due to the importance of soil cover in the region, the pixels of the studied area, which had soil cover in all three images of 1987, 2000 , and 2017, were extracted based on the soil line analysis in the features space of the near-infrared and red bands Landsat images. Then, the maps of the biophysical characteristics of the years of 1987, 2000, and 2017 for these pixels with the net cover of the soil are shown in Figure 5.
1987

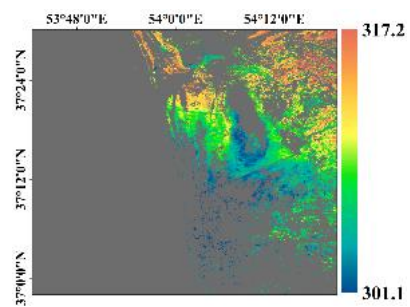

2000

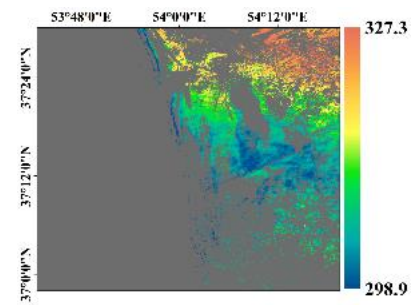

2017

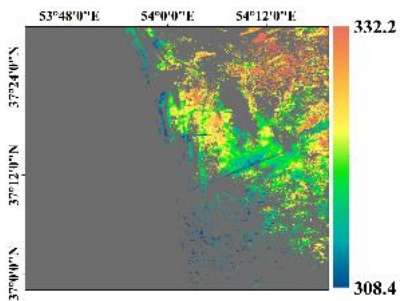


The International Archives of the Photogrammetry, Remote Sensing and Spatial Information Sciences, Volume XLII-4/W18, 2019 GeoSpatial Conference 2019 - Joint Conferences of SMPR and GI Research, 12-14 October 2019, Karaj, Iran

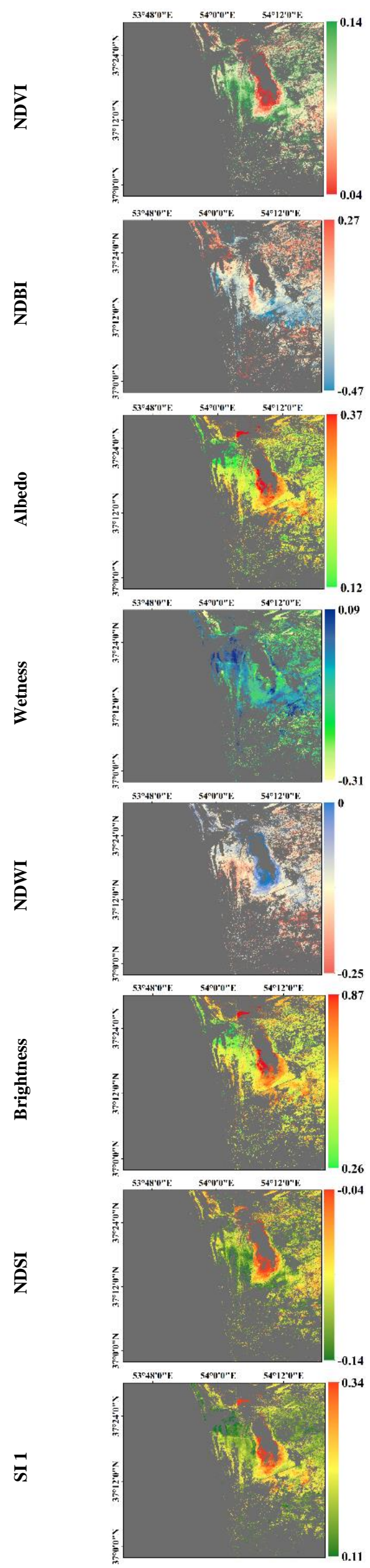

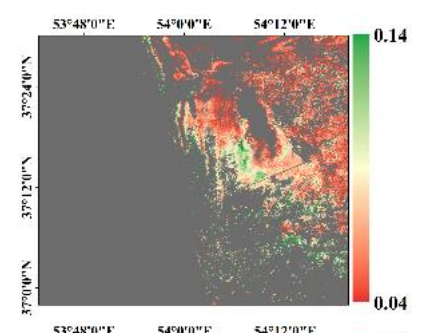
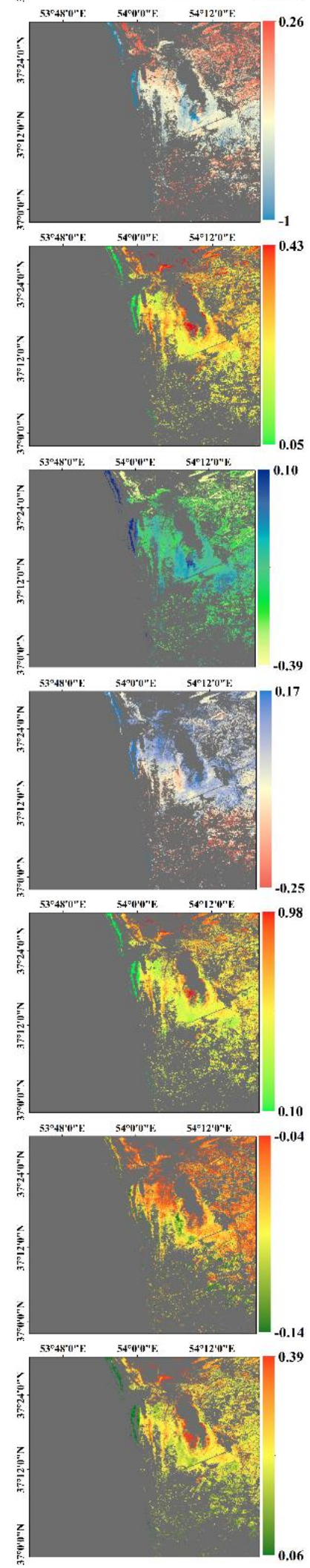
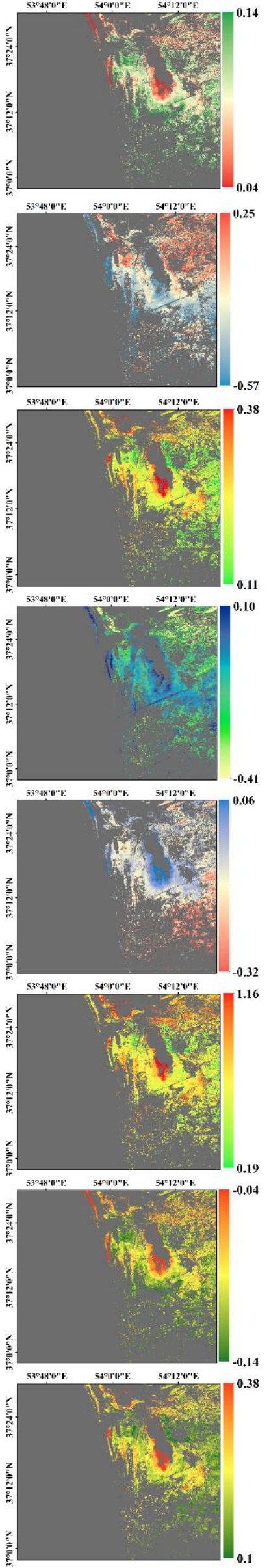
Figure 5. The surface biophysical characteristics maps of the the pixels with soil cover in 1987, 2000, and 2017.

Figure 5 shows that the surface biophysical characteristics changes of the pixels with soil cover in 1987, 2000, and 2017 are high. For example, soil salinity index values (NDSI and SI 1) in 2000 was higher than in other years for these pixels. The LST of these pixels in the north is higher than the south of the study area. Also, wetness of these pixels in the northern regions lower than the southern regions of the study area.

\section{CONCLUSIONS}

One of the important factor affecting the soil forming processes in a region is climatic conditions. Also, Land Surface Temperature (LST) and surface biophysical characteristics are effective parameters on the climatic conditions of a region. In this study, the spatial and temporal changes of LST and biophysical characteristics of Gomishan area during the period of 2017-1987 was investigated. The results show that, the average of LST and vegetation cover are variable for different years and months. The variance of LST and vegetation cover for different spatial location are variant. The maximum LST changes for the study area are related to seasonal wetlands and Gomishan wetland. The main reason for this is the changes of the water level of the wetlands. Generally, for the study area, changes of LST and vegetation cover attributed to changes of the surface biophysical characteristics, increased human activity, increased salt-marsh lands, and the advance and subsequent water level of the Caspian Sea and changes of the water level of the Gomishan wetland. Spatially, the maximum variation of surface biophysical properties (surface temperature, vegetation cover, surface Brightness, surface Wetness and salinity level) in the study area are related to Gomishan wetland. The LST of the pixels with full cover soil in the north is higher than the south of the study area. Also, wetness of these pixels in the northern regions is lower than the southern regions of the study area.

\section{ACKNOWLEDGEMENTS}

This study was supported by the Iran National Science Foundation (grant No. 96003646) and Russian Foundation for Basic Research (grant No. 17-55-560006).

\section{REFERENCES}

Baig, M.H.A., Zhang, L., Shuai, T., \& Tong, Q. (2014). Derivation of a tasselled cap transformation based on Landsat 8 at-satellite reflectance. Remote Sensing Letters, 5, 423-431 Brady, N.C., \& Weil, R. (2013). Nature and properties of soils, the: Pearson new international edition. Pearson Higher Ed Buol, S.W., Southard, R.J., Graham, R.C., \& McDaniel, P.A. (2011). Soil genesis and classification. John Wiley \& Sons Davidson, E.A., \& Janssens, I.A. (2006). Temperature sensitivity of soil carbon decomposition and feedbacks to climate change. Nature, 440, 165

Gao, B.-C. (1996). NDWI-A normalized difference water index for remote sensing of vegetation liquid water from space. Remote Sensing of Environment, 58, 257-266

Jafari, M., \& Sarmadian, F. (2003). Fundamental of soil science and soil taxonomy. University of Tehran publications, $800 p$

Jimenez-Munoz, J.C., Sobrino, J.A., Skokovic, D., Mattar, C., \& Cristobal, J. (2014). Land Surface Temperature Retrieval Methods From Landsat-8 Thermal Infrared Sensor Data. Ieee Geoscience and Remote Sensing Letters, 11, 1840-1843
Kirschbaum, M.U. (1995). The temperature dependence of soil organic matter decomposition, and the effect of global warming on soil organic C storage. Soil Biology and biochemistry, 27, 753760

Lal, R. (2004). Soil carbon sequestration to mitigate climate change. Geoderma, 123, 1-22

Liang, S. (2001). Narrowband to broadband conversions of land surface albedo I: Algorithms. Remote Sensing of Environment, 76, 213-238

Panagopoulos, T., \& Hatzistathis, A. (1995). Early growth of Pinus nigra and Robina pseudoacacia stands: contributions to soil genesis and landscape improvement on lignite spoils in Ptolemaida. Landscape and Urban Planning, 32, 19-29

Peizhen, Z., Molnar, P., \& Downs, W.R. (2001). Increased sedimentation rates and grain sizes 2-4 Myr ago due to the influence of climate change on erosion rates. Nature, 410, 891 Seybold, C., Herrick, J.E., \& Brejda, J. (1999). Soil resilience: a fundamental component of soil quality. Soil Science, 164, 224234

Sobrino, J.A., Jimenez-Munoz, J.C., \& Paolini, L. (2004). Land surface temperature retrieval from LANDSAT TM 5. Remote sensing of environment, 90, 434-440

Tucker, C.J. (1979). Red and photographic infrared linear combinations for monitoring vegetation. Remote sensing of environment, 8, 127-150

Wagenet, R., \& Hutson, J. (1997). Soil quality and its dependence on dynamic physical processes. Journal of Environmental Quality, 26, 41-48

Zha, Y., Gao, J., \& Ni, S. (2003). Use of normalized difference built-up index in automatically mapping urban areas from TM imagery. International Journal of Remote Sensing, 24, 583-594 